\title{
O TURISMO E A EXPANSÃO DAS SEGUNDAS RESIDÊNCIAS NAS LOCALIDADES DE AREMBEPE E IMBASSAÍ NO LITORAL NORTE DA BAHIA
}

Maria Tuanne Brito Silva ${ }^{1}$; Telma Maria Sousa dos Santos ${ }^{2}$

1. Bolsista PIBIC/FAPESB, Graduando em Geografia, Universidade Estadual de Feira de Santana, e-mail: Mari-any@ hotmail.com

2. Orientador, Departamento de Ciências Humanas e Filosofia, Universidade Estadual de Feira de Santana, e-mail: Telmaarq@yahoo.com.br

PALAVRAS-CHAVE: Turismo, Espaço Urbano-Turístico, Segunda Residência

\section{INTRODUÇÃO}

De acordo com Cruz (2003) o turismo é uma atividade econômica e uma prática social que se caracteriza pelo deslocamento de pessoas pelo território, envolvendo a utilização de algum meio de transporte e ao menos um pernoite no local visitado, esse deslocamento pode ser motivado por diversas razões como por exemplo lazer, negócios, estudos ou trabalho. Atualmente, considera-se um turista aquele indivíduo que realiza uma viagem com permanência menor do que um ano em uma área que não é de sua convivência.

A Geografia, ciência cujo objeto de estudo é o espaço geográfico, tem procurado estudar esta atividade considerando a sua dimensão espacial. O espaço é apropriado, produzido e reproduzido por essa atividade que o molda de acordo com suas necessidades com o intuito de torná-lo adequado para o seu funcionamento. É importante ressaltar que o turismo busca se apropriar de áreas que forneçam subsídios para o seu desenvolvimento, desse modo a atividade turística tende a se estabelecer em lugares providos de infraestrutura urbana e potencialidades sejam elas naturais, culturais ou construídas que despertem o interesse do visitante.

As segundas residências são um exemplo da capacidade que o turismo tem "de criar e reproduzir os lugares a sua conveniência" (Cruz, 2003, p. 60). Esse tipo de alojamento configura-se como um meio de hospedagem que está vinculada ao turismo de finais de semana, feriados e períodos de férias. As segundas residências estão presentes nas localidades litorâneas e interioranas, muito embora no Brasil elas se apresentem com maior intensidade no litoral.

As segundas residências em espaços turísticos principalmente nos litorâneos tendem a promover a urbanização dessas áreas. Nesse sentido Santos, baseada nas ideias de Moraes (2007), aponta que as residências de veraneio são um elemento expressivo da urbanização de áreas litorâneas no Nordeste. A autora ainda ressalta que o fenômeno da segunda residência está relacionado com a valorização das praias e o crescimento da procura do turismo sol e mar, a especulação imobiliária e a ideia disseminada de que para se ter lazer deve -se ausentar da sua residência fixa.

Desse modo, esta pesquisa teve por objetivo geral analisar como o turismo tem promovido a expansão das segundas residências nas localidades de Arembepe e Imbassaí no Litoral Norte da Bahia. Esse trabalho focaliza as localidades de Arembepe e Imbassaí que nos últimos anos passaram por um intenso processo de urbanização e requalificação urbanística dos seus espaços, as ações realizadas contribuíram para a 
valorização desses espaços para o turismo, bem como, influenciaram a ocupação dessas áreas através dos hotéis, pousadas e das segundas residências.

\section{MATERIAL E MÉTODOS}

Em função das dificuldades encontradas para a realização dos trabalhos de campo foi necessário repensar a metodologia da pesquisa, a alternativa buscada foi a utilização de um método de procedimento denominado Cartografia Participativa, onde a população se torna protagonista da espacialização do fenômeno investigado. A cartografia participativa permite às populações desenhar, com ajuda de profissionais, mapas dos territórios que ocupam, tomando conhecimento dos fenômenos ali distribuídos. A espacialização das áreas de maior concentração das segundas residências nas áreas estudadas foi realizada a partir das imagens coletadas no Google Earth do satélite CNE/Astrium do ano de 2015.

Para o desenvolvimento da pesquisa foi realizado o levantamento bibliográfico em gabinete para a construção da fundamentação teórica, em seguida, foi realizada a coleta e análise das fontes secundárias, obtidas através de revistas, sites, livros e artigos científicos. Nesta primeira fase da pesquisa foram utilizados também materiais do Grupo de pesquisa Espaço Turismo e Meio Ambiente - GETAM. O próximo passo realizado para o desenvolvimento da pesquisa, foi a realização de dois trabalhos de campo, no primeiro foi realizado o reconhecimento da área de campo, e no segundo a identificação das áreas de maior concentração de segundas residências em Arembepe e Imbassaí, além da coleta de informações através de conversas com moradores locais. Após a coleta dos dados em gabinete e em campo iniciou - se a avaliação dos dados obtidos para a sistematização e elaboração dos resultados finais da pesquisa.

\section{RESULTADOS E/OU DISCUSSÃO}

Através do desenvolvimento da pesquisa foi possível perceber que as segundas residências de Arembepe e Imbassaí são utilizadas com maior frequência no verão, mais especificamente nos meses de dezembro, janeiro e fevereiro. No período de inverno, baixa temporada, os imóveis ficam fechados ou são muito pouco utilizados. Geralmente os domicílios secundários são utilizados por famílias que alugam casas para passar temporada (finais de semana, feriados e férias), ou tem residência secundária própria nas localidades.

Pode-se perceber que as residências secundárias de Arembepe em sua grande maioria são propriedades pertencentes a indivíduos que residem nas cidades de Salvador e Camaçari, sendo que muitos proprietários alugam esses imóveis para visitantes oriundos da cidade de Salvador e Região metropolitana, principalmente nos períodos de alta estação, onde há uma maior procura. No que se refere a Imbassaí observou-se, que as residências secundarias em sua grande maioria são pertencentes a indivíduos que tem a sua residência principal na cidade de Salvador.

A partir de relatos de moradores foi possível identificar e caracterizar as áreas de maior concentração de segundas residências próximas ao núcleo antigo da localidade de Arembepe (Figura 1). É importante ressaltar que identificou-se outras áreas onde também existem casas de veraneio são elas os loteamentos: Vilarejo, Volta do Robalo, 
Capivara e Nova Capivara, porém o enfoque das discussões será dado apenas aquelas nas quais foi possível observar uma maior concentração de moradias destinadas ao uso secundário. Na área estudada foram identificadas duas áreas de maior concentração de segundas residências, a primeira encontra-se situada no loteamento Caraúna uma área de lagoa que ao longo do tempo foi sendo ocupada. A expansão dessa área residencial ocasionou o surgimento de problemas ambientais em decorrência do soterramento das lagoas como o alagamento constante de algumas ruas, mesmo no período de menor ocorrência de chuvas. Sobre as segundas residências situadas nessa área foi possível observar a existência de vilajes e casas individuais que apresentam padrão médio, sendo que algumas tem mais de um pavimento.

\section{FIGURA 1: ÁREA DE CONCENTRAÇÃO DE SEGUNDAS RESIDÊNCIAS EM AREMBEPE}

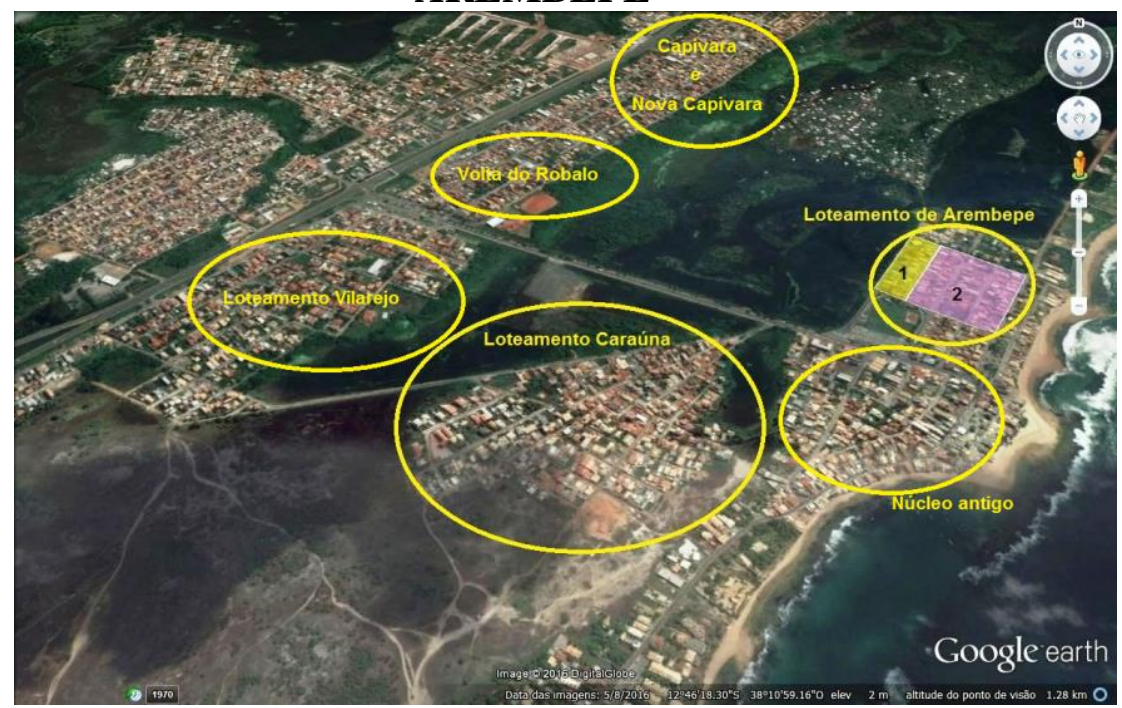

Fonte: Google Earth, 2015.

A segunda área de maior concentração de segundas residências fica situada no loteamento Arembepe, que apresenta uma mistura de residências permanentes e de veraneio, algumas casas possuem área de lazer interna com jardim e piscina e mais de um pavimento. É valido ressaltar que as áreas de concentração de segundas residências identificadas na localidade de Arembepe encontram-se situadas próximo a praia como pode ser observado na imagem acima.

No que se refere a Imbassaí foi possível identificar uma única área de maior concentração de segundas residências que é chamada de vila de Imbassaí (Figura 2) a área fica na área central da localidade, nas proximidades do rio Imbassaí e da praia. A partir das ações de urbanização realizadas na localidade, a infraestrutura urbana foi melhorada e o acesso à praia facilitado em função da construção da ponte sobre o rio Imbassaí que liga a vila a praia. No que se refere às segundas residências foi possível perceber que estas apresentam um alto padrão, são casas grandes de um único pavimento construídas em extensos terrenos. De acordo com os moradores os indivíduos que utilizam esses imóveis nos períodos de alta estação, em sua maioria são oriundos da cidade de Salvador, geralmente as residências são ocupadas por muitas famílias que dividem o aluguel da casa. Ainda de acordo com informações fornecidas por moradores locais que residem na vila os veranistas se deslocam para a localidade de 
Imbassaí em carros próprios e consideram a localidade com boa oferta de comércio e serviços como mercados, sorveterias, bares, restaurantes e etc.

\section{FIGURA 2: ÁREA DE CONCENTRAÇÃO DE SEGUNDAS RESIDÊNCIAS EM IMBASSAÍ}

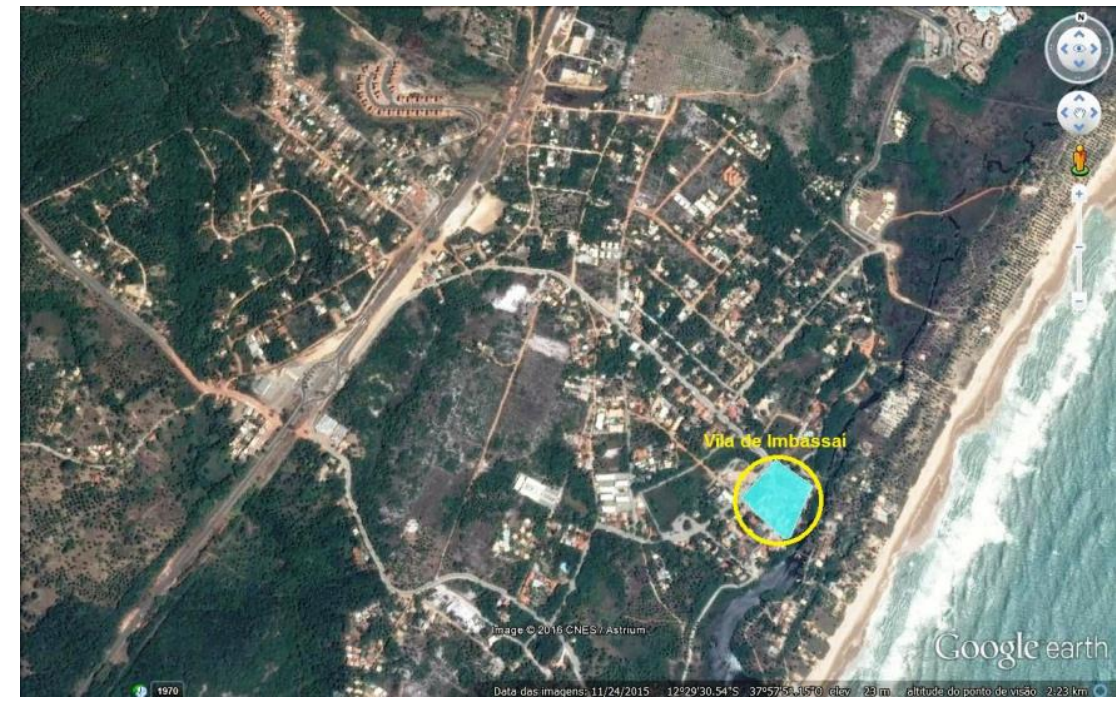

Fonte: Google Earth, 2015.

\section{CONSIDERAÇÕES FINAIS}

A partir do desenvolvimento da pesquisa compreendeu-se que o turismo é uma atividade que estimula a produção do espaço a partir principalmente das segundas residências, e que estas impulsionaram a urbanização das áreas costeiras. Pode-se perceber a partir do desenvolvimento da pesquisa que o turismo tem contribuído para a expansão das segundas residências nas localidades estudadas, pois para que os visitantes passem um determinado período nesses locais é necessário que os mesmos utilizem um alojamento turístico, quando se viaja com a família ou em grandes grupos é mais vantajoso do ponto de vista econômico utilizar a segunda residência, seja ela alugada ou própria. Desse modo, as ações voltadas para a urbanização e requalificação urbanística dos espaços das localidades estudadas promovidas pelo poder público junto com a iniciativa privada tem contribuído para consolidar as localidades estudadas enquanto centros receptores de turistas, principalmente a partir da construção de meios de hospedagem como as segundas residências.

\section{REFERÊNCIAS}

CRUZ, Rita de C. A. Introdução a Geografia do Turismo. São Paulo/SP: Roca, 2003.

SANTOS, Telma Maria Sousa dos. Turismo e urbanização em espaços litorâneos: um olhar sobre Praia do Forte-Bahia. Feira de Santana: UEFS, 2013.

REJOWSKI, Mirian. Turismo no percurso do tempo. 2. Ed. São Paulo/AP: Aleph, 2002.

TULIK, Olga. Turismo e meios de hospedagem: casas de temporada. São Paulo: Roca, 2001. 